October 12, 2003

\title{
Suicide-Bombing as Inter-Generational Investment
}

\author{
by Jean-Paul Azam, \\ University of Toulouse and Institut Universitaire de France, \\ ARQADE, IDEI, and CSAE, Oxford.
}

\begin{abstract}
A simple model of terrorism is presented where the current generation is linked to the next one by some altruism, as in standard dynastic family models. Bombing today some target increases the probability of the benefit of some public good accruing to the next generation. The model is used to discuss the fact that suicide bombers, of the Hezbollah in particular, have been found by Krueger and Maleckova (2002) to come disproportionately from wealthy families, and have an above average education level. While the latter could be expected to increase the opportunity cost of investing in such a suicide, it is suggested that it probably increases also the sensitivity to the future generation's welfare. The latter effect might offset the deterrent effect of the former.
\end{abstract}

Corresponding Author:

Jean-Paul Azam,

ARQADE, University of Toulouse 1,

21, Allée de Brienne,

31000 Toulouse, France.

E-mail: azam@univ-tlse1.fr 
"I hope the Russians love their children too"

Sting (1985)

\section{Introduction}

The events of September 11, 2001 have dramatically attracted the attention of the world to the threat imposed by terrorists who are determined to die for reaching their targets. The layman is staggered by the massive destruction of lives and property that can result from such a strategy. A large number of similar events took place after that, where one or several suicide bombers managed to kill a lot of innocent civilians, in Bali, Casablanca, Mombasa, Ryad, or elsewhere, fortunately on a smaller scale than on September 11, 2001. It seems too easy to assume that the suicide-bombers have been manipulated, and are somehow acting under the influence of irrational passions, drugs, or some kind of psychological subjugation. In fact, the evidence seems to point in the other direction, as terrorists seem to be recruited disproportionately among fairly educated people, and often need the full control of their mental ability for succeeding in their lethal project. The pilots who crashed the September 11 planes on the side of the Twin Towers and the Pentagon, on behalf of Al-Qaeda, as well as several of their accomplices, entered the USA as students, and had a fairly high educational background. Krueger and Maleckova (2002) have used some survey evidence from several sources to document the fact that the terrorists from the Hezbollah, in Lebanon, are coming from relatively wealthy families, and have received an above-average level of education. Paz (2000) describes how the development of higher education institutions throughout the West Bank and the Gaza Strip went hand in hand with the expansion of the Hamas and Islamic Jihad movements, which are actively involved in terrorist activity. Similarly, a small sample of 27 Israeli terrorists from the late 1970s and early 1980s, who attacked Palestinians in the West Bank, is described by Krueger and Maleckova, and shows the same pattern of above-average education and high-paying occupation. This pattern does not apply only in the Middle East, and Russell and Miller (1983) have identified the same characteristics while considering 18 revolutionary groups including the Italian Red Brigades and Japanese Red Army, as well as the German Baader- 
Meinhof Gang. Anecdotal evidence, like the curriculum vitae of the Corsican nationalists involved in the recent murdering of prefect Erignac, in France, suggests that this might also be the case in other movements. These people are teachers, related to academics from Corte University. Although evidence is lacking for concluding that this observation is a general result, applicable to all kinds of terrorist activities, it sets the stylized facts that we have to work with until evidence to the contrary is produced. These results put out a challenge to the economic theorist, to provide some underpinnings to such a behavior, while applying the tools of rational choice theory. Wintrobe (2003) has explored this issue, offering a theory of "belonging-ness", where individuals give up autonomy for acquiring solidarity. Then, as their autonomy erodes, individuals can be pushed to a corner solution, where they give up everything for the sake of the group.

The present paper is an attempt at providing another, more straightforward, type of theoretical underpinning, by working out the implications of the assumption that suicide bombing can be viewed as a form of inter-generational investment. It is assumed that the current generation is trading off its own consumption to day, against the consumption of its descendants to morrow. Within such a framework, reducing current consumption to zero in order to have the maximum potential impact by committing a suicide bombing, can be viewed as an extreme form of saving, whose benefit will entirely accrue to the next generation, with some probability. Dynastic models, where one generation comes after the other, but in such a way that the welfare of the present generation is affected by that of the subsequent ones, are now common in macroeconomics, and in some other fields of economic research. It was made especially popular by Barro (1974). The latter used such a framework to show why government bonds are not net wealth, except under special circumstances. Current savers take into account the present value of future tax liabilities, even if they are meant to fall on a subsequent generation, for making their consumption and saving decisions. The current generation will save more in response to an increased fiscal deficit, for accumulating an increased bequest, with a view to reduce the additional tax burden imposed on the future generation. Further results have been presented by Barro and Becker (1989), which made this type of model a staple in economic research. The present model 
belongs to this lineage of models, but is restricted to two generations only, for the sake of simplicity. This turns out to be sufficient for the purpose at hand, which is to check whether such a theoretical construct can be consistent both with rational choice, and with the abovementioned stylized facts identified by Krueger and Maleckova (2002), among others.

The model presented also belongs to the burgeoning literature on the economics of conflict. This literature made it first to the main economics journals in the first half of the 1990s, starting with the seminal papers by Grossman (1991) and Hirshleifer (1991). These models are somehow related to the rent-seeking literature, and Neary (1997) provides a systematic comparison between the two. The mainstay of such models is the assumed fighting technology, whereby the forces engaged by the two sides are transformed into some probability distribution over the possible outcomes of the fight. Typically, the fight determines which of the contenders is going to get the prize, namely some valuable resources which are out for appropriation, with an endogenously determined probability. A related assumption is made below in the model, which assumes that the resources invested by the current generation in bombing some target affect the probability that the next one will benefit from some public good. The latter can be interpreted in a variety of ways: it can capture some fairly symbolic assets like freedom or national independence, or more downto-earth ones, like the control over some resources, like aquifers or oil fields, which the group could acquire in the future. The target represents for example an occupation army, or some enemy that controls access to the disputed resource. Among the puzzles raised by the literature on conflict is the observation that in the real world, most of the violence going on during civil wars does not take place between the contending armies, but falls disproportionately on civilians. Azam (2002) and Azam and Hoeffler (2002) investigate the potential explanations for such a phenomenon, from both a theoretical and an empirical point of view. They conclude tentatively that violence against civilians is probably aimed mainly at terrorizing them, in order to clear the ground from any potential hiding places, and potential popular support, that guerillas might use, while looting plays probably a secondary role. However, the evidence on which these hypotheses can be tested is fairly scant, and no firm conclusion can yet be drawn. Violence against civilians is one of the 
obvious similarities between civil wars and terrorism. The attack on the twin towers on September 11, 2001 have killed more than 3000 civilians, while they involved no direct confrontation between fighters. However, it is unlikely that the motivations of terrorists are the same as those of under-paid soldiers in poor countries, when they raid villagers. Nevertheless, the target of bombing could thus be assumed to be some civilian population, in the model presented below.

This economic literature on conflict is well suited for analyzing civil wars, or even inter-state wars. However, it does not seem immediately applicable to the issue of terrorism. The economic literature on terrorism has also been active in recent years. Sandler and Arce (2002) and Sandler and Enders (2002) present rich surveys of this field of research, devoting a lot of attention to transnational terrorism, a topic that Addison and Murshed (2002) analyze also. The spillovers from the Israeli-Palestinian conflict to the rest of the world have obviously attracted some attention in this line of research. Abadie and Gardeazabal (2003) have produced an econometric analysis of the case of the Basque country, where external intervention is negligible, providing an estimate of the economic cost of the terrorist activity of the ETA for that area, amounting to more than $10 \%$ of its income. However, quite a lot of work remains to be done in the microeconomic analysis of terrorism, in order to capture some of its salient features. Beside the targeting of innocent civilians, mentioned above, a striking fact is the frequent occurrence of suicide bombing. The activists often do not hesitate to sacrifice their own life for achieving their purpose. This makes deterrence especially difficult, as these activists cannot be discouraged by the simple threat of being killed. Recent accounts of this fact, especially in newspapers, emphasize the culture of "martyrdom" as a cause of this frequent occurrence. However, this is not especially helpful for devising a strategy for reducing it, as religious conversion of the terrorists does not look like a very promising avenue to follow. The present paper tries to offer a more fruitful approach, by looking at the potential microeconomic determinants of this behavior. In particular, it addresses the debated issue of the links between poverty and terrorism. Krueger and Maleckova (2002) report, and challenge on the basis of their empirical evidence, some declarations by the US administration that list the fight against poverty as a tool for the 
global fight against terrorism. President George W. Bush is widely cited to have said: "We fight against poverty because hope is an answer to terror", on March 23, 2002, in Monterrey, Mexico. The theoretical model discussed below concurs with the Krueger-Maleckova negative statistical diagnosis, suggesting also that wealth probably affects positively investment in terrorist activity. However, it allows to look at other parameters that are plausibly affecting the willingness of some agents to invest resources in terrorism, and that might open other avenues whereby aid may have a beneficial effect against terrorism.

The next section shows how a larger initial wealth can lead in such a context to more, rather than less, investment in bombing. This result, which is consistent with the evidence cited above, comes in direct opposition to those who believe that fighting terrorism could be most efficiently performed by fighting poverty. The model and the evidence presented above, point precisely in the opposite direction. However, the same model predicts that investment in bombing would be reduced if the unit cost of doing so increased. If the unit cost of bombing increased, the model predicts that the representative agent would reshuffle his outlays in favor of current consumption, and away from investment for the sake of the next generation. However, the cost of investing in bombing is made of two things, at least. There is first, of course, the direct cost of performing the terrorist attack, which may involve the use of some costly resources, but the main cost is probably the opportunity cost of putting one's life at risk, or even deciding to destroy it with probability one. Then, of course, the evidence that more educated people tend to invest more frequently in terrorist attacks, including suicide bombing, seems to contradict this prediction. The salience of this puzzle is mitigated in the case described by Krueger and Maleckova (2002) by the fact that the economic position of the more educated Palestinians deteriorated markedly in the late 1980s, while the supply of educated Palestinians on the labor market increased massively. Nevertheless, as the relatively high level of educational attainment by terrorists has been observed elsewhere also, this remains an important challenge for theoretical analysis.

The subsequent section brings out another possible channel whereby education may affect the choice of investing in a bombing attack. It is plausible that education affects deeply one's view of the world, enhancing the sensitivity to the future. By enlarging one's 
perception of the world and of the fate of future generations, education is known to have such an effect in the field of ecology, for example. Only fairly educated people understand the need to invest resources in protecting biodiversity, or other ecological assets. Similarly, one may argue that education makes many people more sensitive to other forms of public goods that are bound to affect the welfare of the generations to come. Moreover, beside this formation effect, there is also a simple selection effect: people who are prepared to invest many years in learning have probably a lower rate of time preference than people who choose to earn an income earlier in life. In dynastic models, time preference and altruism towards future generations are one and the same thing, roughly speaking. This assumption reinforces the diagnosis that educated people are probably also people with a keener interest in the future generations. In the classic model by Becker et al. (1990), a similar effect is produced by a more roundabout method. There, the parents' degree of altruism toward their children depends negatively on their number, while the latter is a decreasing function of the rate of return to human capital. They thus find in the steady state a positive relation between altruism toward the next generation and the level of investment in education. Rosenzweig (1990) provides some empirical backing to such an effect, using household-level data sets from several countries. Another interesting correlate of high education, which is quite relevant in the present context, can be found in Barro and McCleary (2002). They find that more educated people tend to have stronger religious beliefs. Casual observation also suggests that terrorists, and in particular, suicide bombers, have also stronger religious beliefs, or sometimes stronger ideological beliefs, than the average people.

The implications of this assumption, that more educated people are also more sensitive to the fate of the next generation, is the focus of section 3 below. The latter shows that potential bombers who are more altruistic towards the future generation will invest more in bombing than the others, and are more likely to become suicide bombers. Section 4 offers some extensions, which allow to draw the implications of the model for aid policy. It suggests that, while the mere provision of aid to the countries where terrorists come from is not likely as such to reduce terrorism, because of the Krueger-Maleckova effect described above, there are specific types of aid policies that might work in the right direction. It argues 
that the proximate goal of aid policy is not simply to transfer resources to some recipients, but to create appropriate tradeoffs in order to influence their behavior. The latter point has been made before in the aid literature, but in other contexts (see e.g. Adam and $\mathrm{O}^{\prime}$ Connell, 1999, Azam and Laffont, 2003). This allows to create a link with the issue of the deterrence of terrorism, an issue which has been analyzed before in the literature, with a focus on retaliation (Lee and Sandler, 1989). Section 5 concludes.

\section{Microeconomic Foundations}

Assume that there are $n$ potential bombers, referred to as agents in the following, who can invest an amount $b_{i}$ in bombing some target, at a personal cost $\gamma b_{i}$. Each of them is linked to his descendants by some altruism, captured by the parameter $\delta_{i}$. In the case of the Hezbollah bombers described by Krueger and Maleckova (2002), descendants must be 
benefits of his act that the suicide bomber perceives are probably channeled by family ties. This is also probably assumed by the Israelis, who punish the suicide-bombers' families by destroying systematically their houses. More generally, these people have a sense of the history of the group that they come from, and "descendants" might also be understood as a more abstract concept, like the continuation value of the children from that group. For example, the Hamas movement, one of the largest perpetrators of terrorist violence, is providing education and health care throughout the West Bank and Gaza Strip (Bueno de Mesquita, 2002).

The case of two generations is sufficient for discussing the main issue, and the model is thus restricted to such a setting. Denote $c_{1 i}$ and $c_{2 i}$ agent $i$ 's consumption levels, for himself and his descendant, respectively. His utility function is assumed to be:

$$
v_{i}=u\left(c_{1 i}\right)+\delta_{i} \alpha c_{2 i}
$$

where $u($.$) is increasing and strictly concave, and \alpha>0$ is a constant parameter, reflecting the un-discounted marginal utility of next generation's consumption. This rules out risk aversion for that generation, for the sake of simplicity.

As mentioned in the introduction, the aim pursued through bombing is to increase the probability $p(B)$ that the descendant will enjoy the benefit of some public good or public asset $\omega(B)$, where $B$ is the aggregate level of bombing performed by all the agents. It is natural to assume that:

$$
p^{\prime}(B)>0, \quad p^{\prime \prime}(B)<0, \quad \text { and } \quad \omega^{\prime}(B) \leq 0 .
$$

This captures the positive and decreasing marginal return to bombing, as well as the possible lasting destructive effects of bombing on the future value of the public good available to generation 2. The former corresponds to the standard assumption in conflict theory (see Neary, 1997), taking as given the forces engaged in defense by the target of the bombing. The latter is fairly natural, and captures the damage that might be done to the public good whose control is at stake, as explained in the introduction. 
Define $y$ and $y^{e}$ as some initial endowments of resources, for the current and the future generations, respectively. These are assumed exogenous, and the constraints faced by agent $i$ when seeking to maximize (1) are thus:

$$
\begin{aligned}
& c_{1 i}=y-\gamma \quad b_{i} \geq 0, \\
& b_{i} \geq 0, \\
& c_{2 i}=y^{e}+p(B) \omega(B) \geq 0,
\end{aligned}
$$

and the following definition:

$$
B=b_{i}+\sum_{j \neq i} b_{j} .
$$

No coordination is assumed among bombers, who are playing according to the Cournot-Nash strategy, taking as given the level of bombing performed by the others. This captures the highly decentralized organization which is alleged to characterize some terrorist organizations, including Al-Qaeda. This decentralized organization is emphasized by Bueno de Mesquita (2002), for whom "terror groups [...] are made up of separate cells, each with its own preferences" (p.2). In some other such organizations, some more developed organization is said to be at work. However, what matters in (6) is that any kind of Stackelberg strategy, whereby one bomber would choose his investment level with a view to influence that of others is ruled out. In the real world, one might argue that some terrorists are performing some bombing with a view to influence others, and trigger some imitation. Hence, some kind of group pressure might be important in the real world, and Wintrobe (2003) has taken some significant steps to capture such a behavior. By reference to Occam's razor, this is neglected in the following, as quite a lot of interesting points can be made by using a simple Nash equilibrium framework. Moreover, the decentralized decision assumption made here certainly captures some crucial features of the real world of terrorism. For example, in the case of the Israeli-Palestinian conflict, there is a large number of groups acting concurrently (Hamas, Hezbollah, Islamic Jihad, etc.), while these groups also have a very loose-knit organization, in order to avoid easy detection (Karmon, 2000). Similarly, 
Orbach (2001) uses the expression "umbrella framework of groups" to describe the organizational structure of Al-Qaeda (Orbach, 2001, p.57).

Definitions 1: (i) agent $i$ 's discounted value of bombing, or his willingness to pay for it, is defined as $\delta_{i} \psi(B)$, where:

$\psi(B)=\alpha\left(p^{\prime}(B) \omega(B)+p(B) \omega^{\prime}(B)\right)$

(ii) his supply price is:

$\gamma u^{\prime}\left(c_{1 i}\right)$

and

(iii) suicide bombing by agent $i$ is defined as occurring when:

$b_{i}=y / \gamma$, i.e. $c_{1 i}=0$.

Notice that agent $i$ 's value of bombing is not necessarily positive, as the second term on the right-hand side of (7) is negative. Hence, the net effect is positive if the increased probability of the public good accruing to the next generation offsets the reduced value of this good due to bombing. However, it is shown below that it is positive in some type of equilibrium, where positive bombing occurs. The supply price represented by (8) reflects the value of the foregone consumption required for effecting the investment in bombing. Because of decreasing marginal utility, this is increasing in the amount of resources invested in bombing by individual $i$. Suicide bombing is defined in (9) as an extreme form of saving, as agent $i$ is giving up any current consumption for the sake of increasing the future consumption of his descendant.

These definitions allow to establish the following proposition:

Proposition 1: (i) Agent $i$ will invest a positive amount of resources in bombing if:

$\delta_{i} \psi(B) \geq \gamma u^{\prime}(y)$

(ii) he will commit suicide bombing if: 


$$
\delta_{i} \psi(B) \geq \gamma u^{\prime}(0)
$$

Proof: Agent $i$ determines his behavior by maximizing (1) under the constraints (3) through (6). This can be done by using the Kuhn and Tucker theorem, with complementary slackness. Conditions (10) and (11) represent the cases where the non-negativity constraints bearing on $b_{i}$ and $c_{1 i}$ are respectively not binding and binding. QED

It is natural to assume that $\psi^{\prime}(B) \leq 0$, i.e. that agent $i^{\prime}$ s willingness to pay for bombing is decreasing with the level of bombing performed. This requires that:

$$
\frac{\omega^{\prime \prime}(B)}{-\omega^{\prime}(B)} \leq \frac{p^{\prime}(B)}{p(B)}\left(2+\frac{p^{\prime \prime}(B) / p^{\prime}(B)}{\omega^{\prime}(B) / \omega(B)}\right)
$$

This is assumed to hold everywhere, for all relevant values of $B$. It does not seem too restrictive, as it simply requires that the function relating current bombing to the future value of the public good benefiting the next generation $\omega(B)$ be not "too convex", as the right-hand side is positive. This means that the negative impact of bombing on this value remains significant even at high levels of $B$. This ensures that the second-order condition for an interior optimum holds.

Because the supply price of the bombing effort is increasing with the level of investment in bombing, (10) tells us that agent $i$ will increase the latter as long as his willingness to pay for it is larger than that. Moreover, condition (11) tells us that agent $i$ will go to the extreme, and choose the corner solution, when his willingness to pay for bombing remains above his supply price, while he is already investing all his resources in the bombing. Notice that the latter could be ruled out by assuming that the following Inada condition holds:

$$
\lim _{c_{1 i} \rightarrow 0} u^{\prime}\left(c_{1 i}\right) \rightarrow \infty
$$

However, there is no reason to make such an assumption in the present setting. It would imply that the marginal value for agent $i$ of generation 2's consumption would fall to zero as the current consumption level falls to zero. Formally, this would mean that: 


$$
\lim _{c_{1 i} \rightarrow 0} \frac{\delta_{i} \alpha}{u^{\prime}\left(c_{1 i}\right)} \rightarrow 0
$$

This is arguably an undesirable property in a model aimed at capturing the effect of inter-generational altruism. One can argue to the opposite that the history of mankind is full of examples where parents have given willingly their life away for saving that of their children, or of other cherished persons. Therefore, (13) is ruled out in the following.

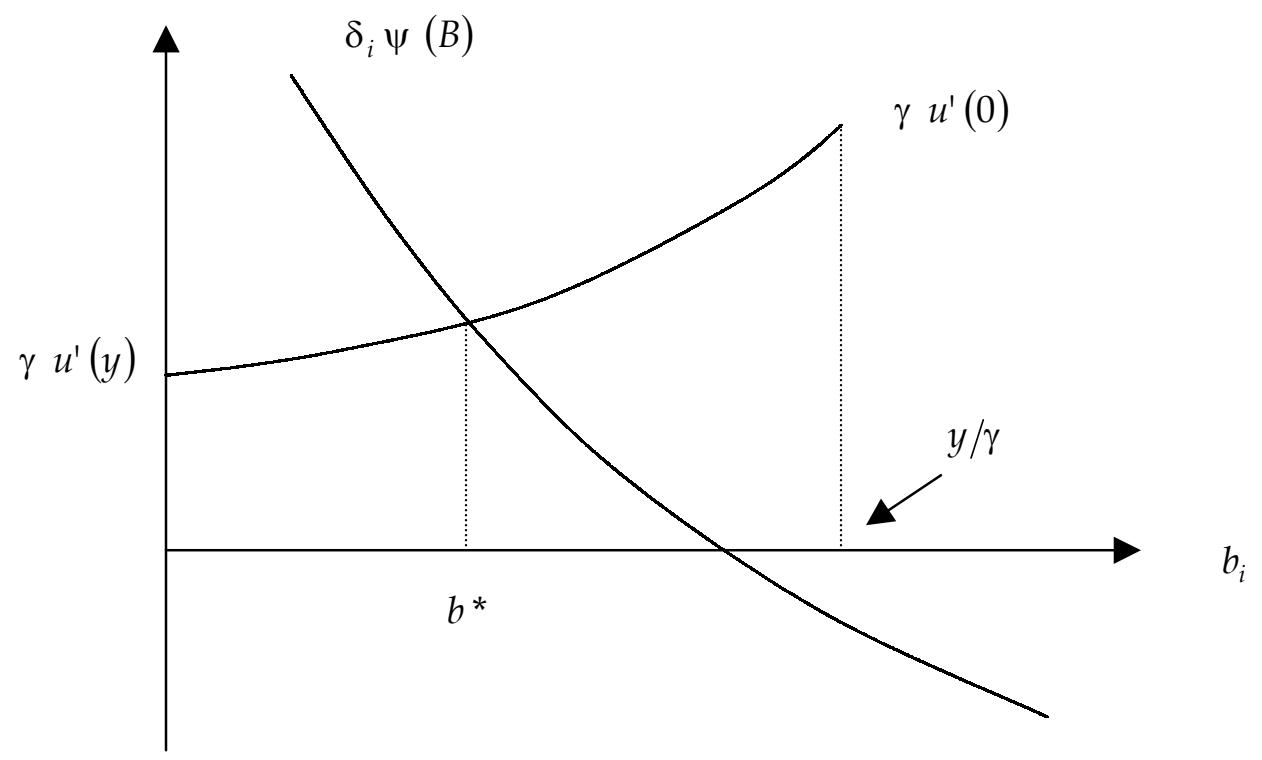

Figure 1: Optimum Investment in Bombing

Figure 1 depicts the choice of agent $i$, when he chooses a positive level of bombing, without committing suicide simultaneously. Such an interior choice of bombing effort is made if (i) $\delta_{i} \psi(0)>\gamma u^{\prime}(y)$, while (ii) $\gamma u^{\prime}(0)>\delta_{i} \psi\left(y / \gamma+\sum_{j \neq i} b_{j}\right)$.

The downward-sloping curve represents agent i's value of bombing, while the upward sloping one represents his supply price. The two curves can intersect for determining an interior solution, as in figure 1, or a suicide bombing choice, if the value curve lies entirely above the maximum supply price, or a no-bombing choice, if it lies entirely below the minimum supply price, on the left-hand side of the diagram. This diagram may be used for performing some comparative-statics exercises. The most important ones are collected in proposition 2 . 
Proposition 2: Agent $i$ 's level of investment in bombing is increasing with:

(i) an increase in the initial endowment $y$,

(ii) a fall in the unit cost of bombing $\gamma$,

(iii) an increase in the degree of altruism towards the next generation $\delta_{i}$,

(iv) a fall in the level of aggregate bombing $B$.

Proof: All these comparative statics results can be generated by shifting the curves of figure 1. The supply-price curve shifts to the right if either $y$ is increased, or if the unit cost of bombing is cut. Moreover, an increase in the degree of altruism towards the next generation shifts the downward-sloping curve upwards, with also a positive impact on the chosen level of bombing effort. Lastly, an increase in the level of aggregate bombing, i.e. by bombers other than agent $i$, shifts the value curve downwards, with a negative impact on agent $i$ 's bombing effort. QED

Notice that while (i) agrees with the Krueger-Maleckova effect described above, (ii) contradicts the observed impact of education, insofar as the latter increases the opportunity cost of getting involved in terrorist activity. Hence, our results suggest that capitalists should generally be expected to get more involved in terrorism than educated workers. The empirical findings by Krueger and Maleckova (2002) mentioned above do not address this issue. The next section argues that education is also correlated with a high degree of altruism in favor of future generations, so that the effect channeled by (iii) might offset the one channeled by (ii). Lastly, the fact that the bombing efforts by the different agents are strategic substitutes, as implied by (iv), is used below for analyzing existence and uniqueness of the Nash equilibrium of this game.

These comparative-statics effects help to describe the response of the individual bomber's behavior to some parametric changes, and do not refer to the properties of the Nash equilibrium. It would be almost trivial to analyze a symmetric equilibrium of this game, assuming that all the agents are identical. Nothing much would be learned on top of the results already derived. It is more interesting to analyze this game in the case where 
some heterogeneity exists among the agents, in order to speak to the empirical results of the Krueger-Maleckova paper. However, for the sake of simplicity, the model is restricted to the case of two types of agents, which is sufficient to bring out the sought result. Moreover, the analysis is focused on the role of the heterogeneous degree of altruism towards the future generation, in order to offer an interesting explanation for the counter-intuitive impact of education mentioned above.

\section{Equilibrium Bombing with Heterogenous Agents}

Assume now that there are two types of potential bombers, differing only by their degree of altruism towards the next generation, with $\delta_{H}>\delta_{L}>0$. Their numbers are $n_{H}$ and $n_{L}$, respectively. For the sake of clarity, proposition 1 can be adapted to the present setting, and rephrased as:

Lemma 1: The bombing supply curve by a type $i$ agent, $i \in\{H, L\}$, may be defined as follows:

$$
\begin{aligned}
& b_{i}=0 \quad \text { if } \quad \delta_{i} \psi(B)<\gamma u^{\prime}(y), \\
& b_{i}=b_{i}(B)<y / \gamma \quad \text { if } \quad \gamma u^{\prime}(y) \leq \delta_{i} \psi(B)<\gamma u^{\prime}(0), \text { and } \\
& b_{i}=y / \gamma \quad \text { if } \quad \gamma u^{\prime}(0) \leq \delta_{i} \psi(B),
\end{aligned}
$$

where $b_{i}(B)$ is such that:

$$
\gamma u^{\prime}\left(y-\gamma b_{i}\right)=\delta_{i} \psi(B)
$$

Proof: Lemma 1 is a straightforward application of proposition 1, using equations (10) and (11). QED

Lemma 1, together with the assumption that $\psi^{\prime}(B)<0$, as discussed above, show that a type $i$ agent will never perform any bombing if $\delta_{i} \psi(0) \leq \gamma u^{\prime}(y)$. This is ruled out in the present section, which emphasizes equilibrium bombing, while it is discussed again in the next section. Similarly, no suicide bombing would ever be performed by type $i$ agent if $\delta_{i} \psi\left(b_{i}\right)<\gamma u^{\prime}(0), \forall b_{i} \geq 0$. This is also ruled out in the present section. 
Notice that (14) can be used to derive the sign of the derivative of $b_{i}(B)$, as:

$$
\frac{\partial b_{i}}{\partial B}=\frac{\delta_{i} \psi^{\prime}(B)}{-\gamma^{2} u^{\prime \prime}\left(c_{1 i}\right)}<0
$$

It is important to notice also that the individual bombing supply curves are continuous, for both types of agents. This can be derived by looking at the response of $b_{i}$ to changes in $B$, for the interior solutions such that (14) holds. At the two extremes of this range one finds immediately that $b_{i}$ tends to zero as $\delta_{i} \psi(B)$ tends to $\gamma u^{\prime}(y)$, while it tends to $y / \gamma$ as $\delta_{i} \psi(B)$ tends to $\gamma u^{\prime}(0)$. This remark, together with the fact that the derivative given in (15) is finite over the relevant range, prove the continuity of $b_{i}$ as a function of $B$.

The aggregate supply curve of bombing effort can now be derived as the sum over all agents of their individual bombing supply curves, as derived in lemma 1:

$$
B^{S}(B)=n_{H} b_{H}+n_{L} b_{L}
$$

This function determines a continuous mapping, which is easily shown to have a fixed point, with $B^{S}(B)=B$, as described below. Moreover, it is easily proved that this function is single-valued and decreasing, although not strictly so, so that this Nash equilibrium is unique.

It is more interesting to characterize this equilibrium, than to prove its existence and uniqueness. Several types of equilibrium can occur in this model, depending on various parameter values. In order to show this, it is convenient to introduce the following notation.

Definitions 2: For $i \in\{H, L\}$, define the four critical points as:

(i) $\quad B_{i}=B \mid \gamma u^{\prime}(0)=\delta_{i} \psi\left(B_{i}\right)$, and

(ii) $\quad B_{y i}=B \mid \gamma u^{\prime}(y)=\delta_{i} \psi\left(B_{y i}\right)$.

Notice that these critical points may fail to exist for some parameter values. Figure 2 helps to understand the role of these critical points. They represent the values of $B$ for which the bombing supply curves of each type have a kink, and change slope, as can be inferred from lemma 1 . Then one derives easily the following rankings: 


$$
B_{L}<B_{H}<B_{y H} \text {, and } B_{L}<B_{y L}<B_{y H} .
$$

However, one cannot rank $B_{H}$ and $B_{y L}$ without further assumptions. This ranking is liable to play a part in determining the properties of the Nash equilibrium, in some cases. A glance at figure 2 shows that $B_{y L}<B_{H}$ when $y$ is "small", and/or $\delta_{H}$ is "large" relative to $\delta_{L}$. In other words, this case occurs when the country is rather poor, and/or has a relatively heterogeneous population. The opposite case occurs when the country is relatively rich, and/or has a more homogenous population. The importance of this ranking comes out clearly from the following exercise.

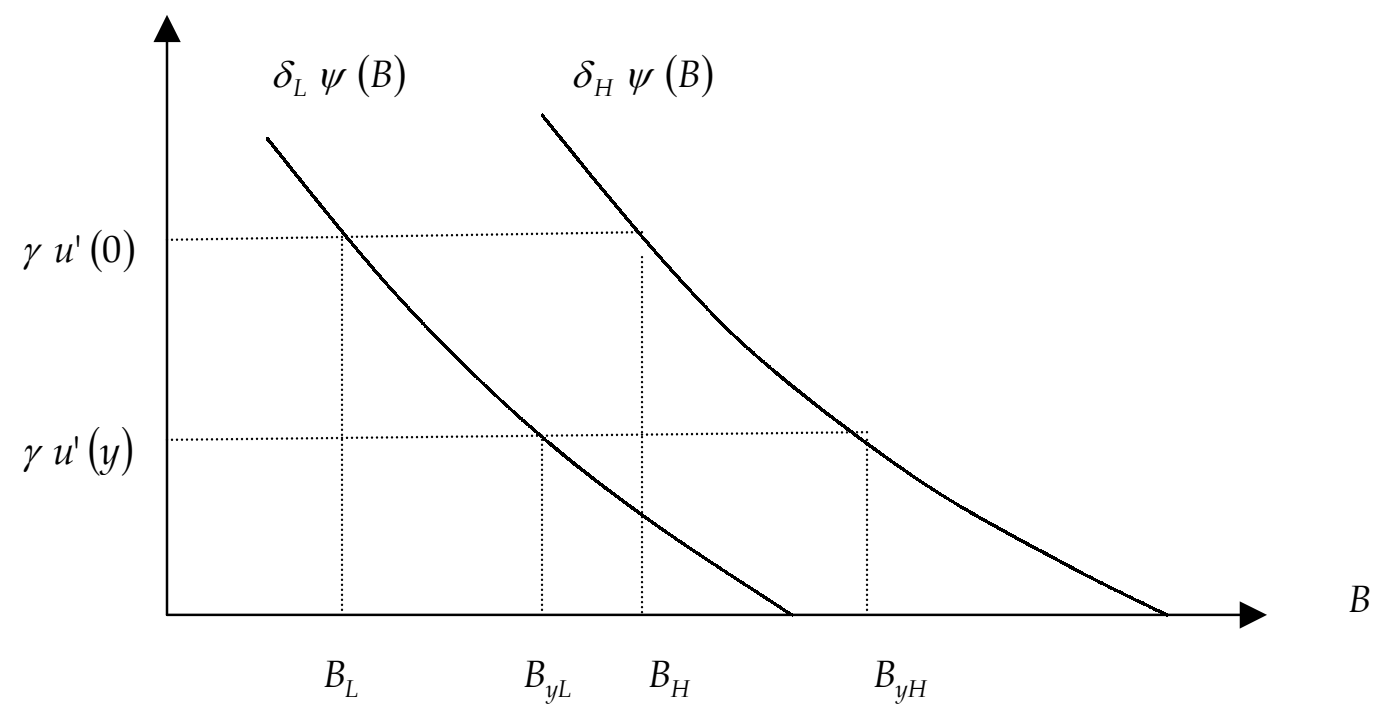

Figure 2: The Critical Points

In the case where $B_{H}<B_{y L}$, the aggregate supply curve of bombing is as follows:

$$
\begin{aligned}
& B^{S}=\left(n_{H}+n_{L}\right) y / \gamma \quad \text { if } \quad B \leq B_{L}, \\
& B^{S}=n_{H} y / \gamma+n_{L} b_{L}(B) \text { if } \quad B_{L}<B \leq B_{H}, \\
& B^{S}=n_{H} b_{H}(B)+n_{L} b_{L}(B) \text { if } B_{H}<B \leq B_{y L}, \\
& B^{S}=n_{H} b_{H}(B) \text { if } \quad B_{y L}<B \leq B_{y H}, \text { and } \\
& B^{S}=0 \text { if } \quad B_{y H}<B .
\end{aligned}
$$

In the opposite case, it has the following form: 


$$
\begin{aligned}
& B^{S}=\left(n_{H}+n_{L}\right) y / \gamma \quad \text { if } \quad B \leq B_{L}, \\
& B^{S}=n_{H} y / \gamma+n_{L} b_{L}(B) \quad \text { if } \quad B_{L}<B \leq B_{y L}, \\
& B^{S}=n_{H} y / \gamma \quad \text { if } \quad B_{y L}<B \leq B_{H}, \\
& B^{S}=n_{H} b_{H}(B) \text { if } \quad B_{H}<B \leq B_{y H}, \text { and } \\
& B^{S}=0 \text { if } \quad B_{y H}<B .
\end{aligned}
$$

The only difference between these two cases can be identified by looking at the third row of these two sets of equations, which are labeled (18) and (19), respectively. In the former case, when equilibrium occurs within the range of values corresponding to (18), we have a fairly homogenous terrorist community, where all the potential bombers are involved in some bombing, while none of them commits suicide bombing. In the case identified by (19), by contrast, we find a fairly polarized community of potential bombers, where the most altruistic ones are engaged in systematic suicide bombing, while the others are not doing any bombing at all. According to the interpretation presented earlier, this is likely to happen within a country which is already quite poor, and/or has a fairly heterogeneous population of potential bombers.

Let us summarize this analysis, while focusing on the cases where suicide bombing occurs in equilibrium, as in proposition 3.

Proposition 3: Let $B^{*}$ denote the equilibrium level of bombing.

(i) Suicide bombing occurs in equilibrium if the latter is such that $B^{*} \leq B_{H}$;

(ii) It is the only type of bombing that occurs in equilibrium if the latter is such that either $B_{y L}<B^{*} \leq B_{H}$ or $B^{*} \leq B_{L}$.

Remark: Proposition 3 could alternatively be expressed as (i) suicide bombing occurs in equilibrium if $B_{H}>B^{S}\left(B_{H}\right)$, and (ii) it is the only type of equilibrium bombing if in addition we have: $B_{y L} \leq B^{S}\left(B_{y L}\right)$ or $B^{S}\left(B_{L}\right) \leq B_{L}$.

Figures 3.a and 3.b represent the two cases where (i) suicide bombing occurs in equilibrium, while (ii) all the potential bombers are not engaging in it. The left-hand panel 
shows the case where the Nash equilibrium involves a positive level of the two types of bombing. In figure 3.b the equilibrium only involves suicide bombing, while the other potential bombers refrain from doing any bombing at all. As discussed above, these different types of equilibrium are likely to emerge in societies that differ either by their income level, or by the degree of heterogeneity of their population. Notice that the present analysis does not preclude that a no-bombing equilibrium might prevail, for some appropriate values of the $\left\{\delta_{H}, \delta_{L}, \alpha, \gamma, y\right\}$ set of parameters such that $B_{y H} \leq 0$.

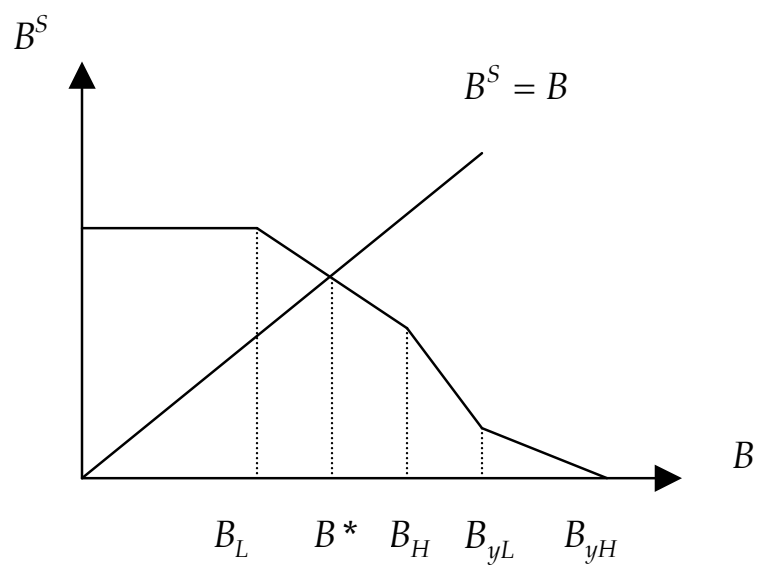

Figure 3.a: Mixed-Type Bombing

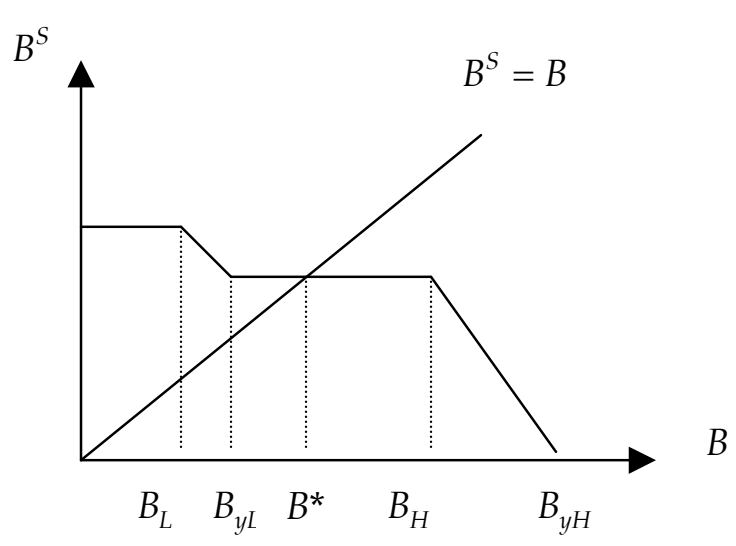

Figure 3.b: Suicide Bombing Only

The bottom line of this section is that suicide bombing can be a perfectly rational outcome within a Nash equilibrium of the present game-theoretic analysis of terrorism. Here, terrorist bombing is viewed as a form of investment performed by the current generation for the expected benefit of the next one. In all the cases where equilibrium involves a positive amount of bombing, the most altruistic agents towards their descendants are supplying more bombing effort than the others. In many cases, identified above, they choose suicide bombing while the others are either supplying a lower level of bombing, or not performing any bombing at all. The next section draws some of the implications of this rational choice approach for the problem of preventing terrorist attacks. Because the threat of such attacks is widely perceived as coming mostly from poor countries, this issue is discussed within the framework of aid policy. As mentioned in the introductory section, the 
role of aid policy within the global fight against terrorism is a debated issue, on which the next section aims at shedding some light.

\section{The Scope for Aid Policy towards the Prevention of Terrorism}

Because of the Krueger-Maleckova effect discussed above, and confirmed from a theoretical point of view in the present setting, the model does not favor policies that simply increase current incomes in risky countries. In order to reduce the incidence of terrorist attacks, and in particular that of suicide bombing, the model leans rather in favor of reducing current incomes in the target population. This hardly qualifies as an acceptable type of aid policy, and would be opposed by a large fraction of the donor community. Nevertheless, the sanctions on Iraq imposed until the US-UK intervention in 2003 come close to fitting this pattern. However, such an aid policy that increases current incomes, period, does not exhaust the list of the possible aid strategies that can be pursued. In fact, the theoretical literature on aid has systematically concluded against unconditional aid. Azam and Laffont (2003), for example, show that while unconditional aid is useless, there are possible methods for using aid as a means to affect the choice of the government of the south. However, their contract-theoretic approach is not the best suited for dealing with the type of decentralized terrorism that is analyzed here. Nevertheless, one basic insight can be imported from this literature, namely that the point about aid is not to transfer resources as such to poor countries. It is to create tradeoffs that lead the target players to change their behavior in a desirable direction.

The present model brings out some of the relevant tradeoffs that an intelligent aid policy should seek to affect. The slope of the function governing the relationship between bombing now and the expected value of the public good available for the next generation, denoted $\psi(B)$ above, is one of the crucial elements that shapes the equilibrium outcome. In fact, the present model expresses the condition for no bombing at all to be performed by agent $i$ as:

$$
\delta_{i} \psi(B)<\gamma u^{\prime}(y)
$$


Therefore, an aid policy aimed at reducing the incidence of terrorism should aim at making equation (20) hold for the largest possible fraction of the population. Taking the degree of altruism towards the next generation as exogenous, as well as the shape of the utility function, this leaves three parameters on which aid policy could try to exert some influence. The first one, already discussed above, would be to reduce income $y$. This has certainly been done before, and one could argue that this is a likely outcome of the imposition of sanctions. Iraq in the 1990s and early 2000s provides an example of such an effect, for a large part of the population. Analyzing whether this experience confirms the results of the present model falls outside the scope of the present paper.

The second potential parameter of interest is the unit cost of performing a terrorist attack. However, the Krueger-Maleckova effect discussed above suggests that affecting $\gamma$ is probably more tricky than it looks. Their empirical results, in the light of the model presented here, suggest that the positive effect of education on the opportunity cost of engaging in terrorism, probably the most important part of such a cost, might be offset by the opposite effect of human capital on the degree of altruism toward future generations. The latter enhances, rather than reduces, the willingness of the potential bombers to engage in bombing.

Therefore, the present analysis suggests that devising an aid policy aimed at reducing the incidence of terrorism should focus on reducing the slope of the function relating the expected value of the future public good to the current level of bombing. It is plausible that a strategy for deterring terrorist attacks should involve the irreversible reduction of the welfare of the future generation, for example through the destruction of some future public goods as a response to them. However, the donor community is probably unable to commit credibly to refrain from allocating aid to countries producing terrorist attacks; it is most likely to flood such countries with reconstruction projects in the future, independently of the incidence of terrorist attacks today. For example, the Security Council of the UN today would be unable to tie the hands of its distant successor 15 years hence, and could not prevent donors from funding reconstruction projects in the future. This problem is an inter- 
temporal version of the "paid-rider" problem analyzed by Lee and Sandler (1989), which shows how a sub-optimal level of retaliation against terrorist attacks is likely to emerge in a multi-country setting. One also hates the idea that the families of terrorist bombers should be directly the target of reprisals, making sure for example that the children that they care for are systematically deprived of schooling and health care in the future. But the present analysis certainly points to a series of potential handles for creating the required tradeoffs.

In order to bring this out, assume that the expected value of the future public good available for the next generation can be written as:

$$
E=p\left(B, a_{p}\right) \omega\left(B, a_{\omega}\right)
$$

where $a_{p}$ and $a_{\omega}$ are two different aid flows, attached to two different types of conditionality or types of projects.

Proceeding as in (7), we find that the marginal value of bombing for agent $i$ is now a function of the two aid flows, and may be written as:

$$
\delta_{i} \psi\left(B, a_{p}, a_{w}\right)=\delta_{i} \alpha\left(p_{B}\left(B, a_{p}\right) \omega\left(B, a_{\omega}\right)+p\left(B, a_{p}\right) \omega_{B}\left(B, a_{\omega}\right)\right)
$$

where a subscript denotes a partial derivative.

Then, it is straightforward to see how the two sets of aid flows should be devised. The first aid window should deliver projects or reforms such that:

$$
p_{a}(.) \geq 0 \text { and } p_{B a}(.) \leq 0
$$

The second aid window should deliver projects such that:

$$
\omega_{a}(.) \leq 0 \text { and } \omega_{B a}(.) \leq 0 \text {. }
$$

In other words, the anti-terrorist aid policy should be devised first so as to increase the probability that the next generation will enjoy the benefit of the expected public good, while making this probability less dependent on current bombing. For example, political concessions that make the availability of the public good certain for the next generation, 
setting in fact $p()=$.1 , are an extreme example of this type of project. Bueno de Mesquita (2002) discusses some of the problems raised by political concession to heterogeneous terrorist organizations, as their more radical members might remain unaffected by them. However, putting this probability equal to zero would also serve the same purpose, but seems more difficult to implement. Less extreme solutions can be sufficient for reducing the attractiveness of terrorist attacks, like military assistance to the target, which makes the probability of victory for the terrorists less sensitive to current bombing. This could be combined with other policies tilting the $E$ function in the right direction. Second, the antiterrorist aid policy should be devised in order to either reduce the value of this future public good, or, more convincingly, to make its value more sensitive to the impact of current bombing. For example, investing massively in tourism would create a constituency in favor of reducing bombing, insofar as the latter keeps tourists away. Enders and Sandler (1991) have provided a seminal empirical analysis of this problem. In the real world, the problem with investment in tourism is that, while it creates some incentive to reduce terrorist activity in the country where the investment is done, it creates ideal targets for other terrorists. Pipelines for transporting oil across the country are also a type of investment that can create a negative link between bombing today and the welfare of the next generation: bombing the pipeline would entail irreversible environmental damage, which educated terrorists are bound to understand. This is true of other types of environmentally hazardous investment projects, like some types of chemical plants, which would leverage significantly any retaliatory action. Some more empirical research is clearly needed to identify reliably the type of development projects that the future generations in the countries of origin of terrorists, or their sponsors, might value, while their benefit would fall significantly in response to current bombing. The seminal paper by Enders and Sandler (1991), about tourism, is certainly showing the way to follow for this type of analysis.

\section{Conclusion}

This paper has exploited the dynastic family hypothesis, which is a staple in modern macroeconomic research, to provide a potential explanation for the remarkable phenomenon 
of suicide bombing. The latter is the hallmark of present-day terrorism, and September 11, 2001 saw its most terrifying effects. The microeconomic analysis of this phenomenon is certainly in its infancy, but some stylized facts have recently begun to be presented that provide some guideposts for devising theoretical models that can explain it. The present paper proposes a theoretical exploration of this field, which reconciles the stylized facts with the assumption of rational choice.

The model views the objective function of the potential bomber as affected by both his current consumption and the expected welfare of his descendants. The latter is comprised of standard consumption, and of the expected value of some future public good. The cause of terrorist attack is that the probability of the next generation benefiting from this public good is positively affected by the amount of bombing performed to day. All the potential bombers decide in a decentralized fashion how much resources they want to invest in bombing, while suicide bombing occurs when they decide to reduce their current consumption level to zero. Then, the model assumes that the usual Inada condition, which assumes that the marginal utility of consumption tends to infinity whenever the consumption level falls to zero, does not hold. This allows for the possibility that the terrorist might rationally choose to engage in suicide bombing. In such a model, suicide bombing is just an extreme form of saving, such that the agent gives up any current consumption for the sake of enhancing the probability of his descendant to enjoy the benefit of the future public good. The bombing effort chosen by the terrorist is shown to increase with current income, to decrease with the opportunity cost of investing some effort in bombing, and to increase with the degree of altruism towards the next generation. It is argued that this might provide a theoretical avenue for reconciling the stylized facts with a simple rational choice model.

Data concerning members of the Hezbollah, in particular, suggest that suicide bombers are coming from above average wealthy families, and have an above average level of education. While the former finding makes perfectly good sense in the present framework, the latter seems to go in the wrong direction. The opportunity cost of sacrificing one's life for a terrorist attack normally depends on the amount of human capital accumulated in the potential bomber, and the latter should thus act as a deterrent to suicide bombing. The model 
presented here argues that there is probably a second channel of influence of education on the willingness to engage in suicide bombing mission, namely through the degree of altruism towards the future generation. This second channel might in fact be the dominant one in the population analyzed by the empirical study described above. The model shows that in the Nash equilibrium of the decentralized bombing game analyzed here, more altruistic people spend more of their resources for performing terrorist attacks, and are in particular more involved in suicide bombing. Conditions are presented for a bombing equilibrium involving suicide bombing to prevail.

The added benefit of this model is that it brings out some channels whereby an intelligent aid policy could be used to reduce the incidence of terrorism. The proposed aidpolicy framework should focus on tilting the relationship between bombing today and the expected value of the future public good to be consumed by the next generation. The aim of such a policy is to change the tradeoff faced by the potential bomber today, in order to reduce the value of giving up his life for enhancing the chances of his descendants to enjoy the benefit of the assumed public good. Investing in tourism infrastructure, for example, has the right property: it makes the future value of the asset decreasing in the quantity of current bombing, which is bound to keep tourists away for a long time. Another example is political concession: if the benefit of the future public good for the next generation is made certain, then bombing today has no more impact on the probability of getting the public good. A more radical type of aid policy would aim at investing in the countries of origin of terrorists, or of their sponsors, in productive, but environmentally hazardous projects. This would produce deterrence somewhat in the same spirit as nuclear dissuasion was doing during the cold war.

\section{References}

Abadie, A. and J. Gardeazabal (2003). The economic cost of conflict: a case study of the Basque country. American Economic Review 93 (1): 113-132.

Adam, C.S., and S.A. O'Connell (1999). Aid, taxation and development in Sub-Saharan Africa. Economics and Politics 11: 225-253. 
Addison, T. and S.M. Murshed (2002). Transnational terrorism as a spillover of domestic disputes in other countries. Unpublished: UNU-WIDER: Helsinki.

Azam, J.-P. (2002). Looting and conflict between ethno-regional groups: lessons for state formation in Africa. Journal of Conflict Resolution 46 (1): 131-153.

Azam, J.-P. and A. Hoeffler (2002). Violence against civilians in civil wars: looting or terror. Journal of Peace Research 39 (4): 461-485.

Azam, J.-P. and J.-J. Laffont (2003). Contracting for aid. Journal of Development Economics 70 (1): 25-58.

Barro, R.J. (1974). Are government bonds net wealth?. Journal of Political Economy 81 (6): 1095-1117.

Barro, R.J. and G.S. Becker (1989). Fertility choice in a model of economic growth. Econometrica 57 (2): 481-501.

Barro, R.J. and R.M. McCleary (2002). Religion and political economy in an international panel. Unpublished: Harvard University, Cambridge, Mass.

Becker, G. S., K. M. Murphy and R. Tamura (1990). Human capital, fertility, and economic growth. Journal of Political Economy 98 (5): S12-S37.

Bueno de Mesquita, E. (2002). An adverse selection model of terrorism: theory and evidence. Unpublished: Harvard University, Cambridge, Mass.

Enders, W. and T. Sandler (1991). Causality between transnational terrorism and tourism: the case of spain. Terrorism 14 (1): 49-58.

Grossman, H.I. (1991). A general equilibrium model of insurrection. American Economic Review 81 (4): 912-921.

Hirshleifer, J. (1991). The paradox of power. Economics and Politics 3: 177-200.

Karmon, E. (2000). Hamas' terrorism strategy: operational limitations and political constraints. Middle East Review of International Affairs 4 (1): 66-79.

Keller, B. (2002). Springtime for Saddam. The New York Times, April 6, p.A15.

Krueger, A.B. and J. Maleckova (2002). Education, poverty, political violence, and terrorism: is there a causal connection?. NBER Working Paper 9074. Cambridge, Mass. 
Lee, D.R., and T. Sandler (1989). On the optimal retaliation against terrorists: the paid-rider option. Public Choice 61 (2): 141-152.

Neary, H. (1997). A comparison of rent-seeking models and economic models of conflict. Public Choice 93 (2): 373-388.

Orbach, B. (2001). Usama Bin Ladin and Al-Qa'ida: origins and doctrines. Middlle East Review of International Affairs 5 (4): 54-68.

Paz, R. (2000). Higher education and the development of Palestinian Islamic groups. Middle East Review of International Affairs 4 (2): 81-94.

Rosenzweig, M. R. (1990). Population growth and human capital investments: theory and evidence. Journal of Political Economy 98 (5): S38-S70.

Russell, C. and B. Miller (1983). Profile of a terrorist. In L.Z. Freedman and Y. Alexander (Eds.), Perspectives on terrorism, 45-60. Wilmington: Scholarly Resources Inc.

Sandler, T. and D.G. Arce M. (2002). Terrorism and game theory. Unpublished: University of Southern California, Los Angeles (Forthcoming in Simulation \& Growing, 2003).

Sandler, T. and W. Enders (2002). En economic perspective on transnational terrorism. Unpublished: University of Southern California, Los Angeles (Forthcoming in European Journal of Political Economy 2004).

Sting (1985). Russians. From The Dream of the Blue Turtle, A\&M Records, Polygram.

Wintrobe, R. (2003). Can suicide bombers be rational?. Unpublished: University of Western Ontario. 